\title{
THE IMPLEMENTATION OF STRATEGIC MANAGEMENT IN THE MANAGEMENT OF STATE ASSETS: AN EMPIRICAL STUDY AT THE OFFICE OF THE MINISTRY RELIGIOUS AFFAIRS OF WONOGIRI REGENCY
}

\author{
Nur Kholistiani ${ }^{1)}$ \\ Lilis Sulistyani $^{2)}$ \\ STIE Adi Unggul Bhirawa Surakarta \\ noer_cholist@yahoo.co.id
}

\begin{abstract}
ABSTRAK
Penelitian ini merupakan penelitian kuantitatif yang bertujuan untuk mengetahui secara empiris implementasi pengelolaan aset pada Kantor Kementerian Agama Kabupaten Wonogiri dengan menggunakan pengaruh kepemimpinan, komitmen organisasi, dan manajemen strategis sebagai variabel intervening. Penelitian ini berupa penelitian dengan metode survey. Data yang digunakan adalah data primer dengan mengambil sebagian populasi untuk sampel sebanyak 50 (lima puluh) responden di Kantor Kementerian Agama Kabupaten Wonogiri. Data dalam riset ini diperoleh secara langsung dari hasil penyebaran kuisioner. Penelitian ini menggunakan alat analisis berupa uji validitas, uji reliabilitas, uji linearitas, analisis jalur dan regresi berganda, uji t, uji $\mathrm{F}$ dan uji determinasi $\left(\mathrm{R}^{2}\right)$. Hasil penelitian ini menunjukkan bahwa kepemimpinan berpengaruh positif dan signifikan terhadap manajemen strategis, komitmen organisasi berpengaruh positif dan signifikan terhadap manajemen strategis, kepemimpinan berpengaruh positif dan signifikan terhadap pengelolaan aset, komitmen organisasi berpengaruh positif dan signifikan terhadap pengelolaan aset, manajemen strategis berpengaruh positif dan signifikan terhadap pengelolaan aset. Hasil uji secara serempak (Uji F) dapat disimpulkan secara simultan variabel kepemimpinan, komitmen organisasi, dan manajemen strategis berpengaruh positif dan signifikan terhadap pengelolaan aset. Hasil uji determinasi menunjukkan bahwa R Square $\left(\mathrm{R}^{2}\right)$ total adalah 0,92 , artinya variabel pengelolaan aset dijelaskan oleh kepemimpinan, komitmen organisasi, dan manajemen strategis sebesar 92\% dan sisanya sebesar 8\% dijelaskan variabel lain diluar model penelitian. Hasil analisis jalur menunjukkan bahwa pengaruh tidak langsung kepemimpinan terhadap pengelolaan aset melalui manajemen strategis lebih besar dibandingkan pengaruh langsung kepemimpinan terhadap pengelolaan aset, pengaruh langsung komitmen organisasi terhadap pengelolaan aset lebih besar dibandingkan pengaruh tidak langsung komitmen organisasi melalui manajemen strategis. Jalur tidak langsung kepemimpinan melalui manajemen strategis merupakan variabel yang paling dominan pengaruhnya terhadap pengelolaan aset. Kepemimpinan melalui manajemen strategis merupakan jalur yang dipilih sebagai jalur yang paling efektif dalam pengelolaan aset.
\end{abstract}

Kata kunci : kepemimpinan, komitmen organisasi, manajemen strategis, pengelolaan aset.

\begin{abstract}
This research is a kuantitatif research, that purpose was to determine empirically the implementation of asset management at the office of The Ministry Religious Affairs of Wonogiri Regency using the influence of leadership, organizational commitment, and strategic management as intervening variables. This study is a survey method based research. The used primary data was done by taking as 50 (fivety) employees at The Ministry Religious Affairs of Wonogiri Regency. Data in this research wald be obtained directly from the results of questionnaires. The analitycal tool used instrument test, linearity test, path analysis and regression with $t$ test, $\mathrm{F}$ test and $\mathrm{R}^{2}$ test. This study result point that leadership had positive and significant influence on strategic management, organizational commitment had positive and significant impact on strategic management, leadership had positive and significant impact on asset management, organizational commitment had a positive and significant impact on asset management, strategic management has a significant positive effect on asset management. The simultaneous result of the test (F test) can be concluded as leadership variables, organizational commitment, strategic management have a positive and significant impact on asset management. The result of determination test shows that $\mathrm{R}$ Square $\left(R^{2}\right)$ total is 0,92 , which means asset management variable is explained by leadership, organizational commitment, and strategic management of $92 \%$ and the rest of $8 \%$ is explained as other variable outside the research model. The results of path analysis shows that the indirect effect of leadership on asset management through strategic management is greater than the direct influence of leadership on asset management, the direct impact of organizational commitment to asset management is greater than the indirect influence of organizational commitment through strategic management.
\end{abstract}


The indirect path of leadership through strategic management is the most dominant variable of its influence on asset management is the path chosen as the most effective path in asset management.

Keywords: leadership, organizational commitment, strategic management, asset management.

\section{PENDAHULUAN}

Perubahan paradigma baru pengelolaan Barang Milik Negara(BMN) atau aset negara telah memunculkan optimisme baru dalam pengelolaan aset negara yang lebih tertib, akuntabel, dan transparan. Pengelolaan aset negara yang profesional dan modern dengan mengedepankan good governance di satu sisi diharapkan akan mampu meningkatkan kepercayaan pengelolaan keuangan negara dari masyarakat atau stakeholder.

Kementerian Agama adalah salah satu entitas akuntansi dibawah Badan Pembinaan Akuntansi Instansi yang berkewajiban menyelenggarakan akuntansi dan laporan pertanggungjawaban atas pelaksanaan Anggaran Pendapatan dan Belanja Negara telah melakukan pengelolaan aset dengan baik walaupun masih banyak permasalahan yang dihadapi. Salah satu buktinya kementerian setelah melakukan Inventarisasi dan Penilaian (IP), dilanjutkan dengan mengeluarkan peraturan-peraturan tentang Pengelolaan Barang Milik Negara. Tindakan ini telah berdampak pada perbaikan Laporan Keuangan Pemerintah dari Wajar Dengan Pengecualian (WDP) menjadi Wajar Tanpa Pengecualian (WTP).

Tabel I.1 Rincian Opini atas LKKL dan LKBUN

\begin{tabular}{|c|c|c|c|c|c|}
\hline \multirow{2}{*}{$\begin{array}{l}\text { Kementer } \\
\text { ian } \\
\text { /Lembaga }\end{array}$} & \multicolumn{5}{|c|}{ Opini BPK atas LKKL } \\
\hline & $\begin{array}{c}201 \\
3\end{array}$ & $\begin{array}{c}201 \\
4\end{array}$ & 2015 & $\begin{array}{c}201 \\
6\end{array}$ & $\begin{array}{c}201 \\
7\end{array}$ \\
\hline $\begin{array}{l}\text { Kementeria } \\
\text { n Agama }\end{array}$ & $\begin{array}{l}\text { WT } \\
\text { P- } \\
\text { DD } \\
\text { P }\end{array}$ & $\begin{array}{l}\text { WT } \\
\text { P- } \\
\text { DD } \\
\text { P }\end{array}$ & $\begin{array}{l}\text { WD } \\
\mathrm{P}\end{array}$ & $\begin{array}{l}\text { WT } \\
\mathrm{P}\end{array}$ & $\begin{array}{l}\mathrm{W} \\
\mathrm{TP}\end{array}$ \\
\hline
\end{tabular}

Sumber: Ikhtisar Hasil Pemeriksaan Semester 2 Tahun 2017 (BPK)

Arah dari langkah-langkah penertiban BMN (inventarisasi dan penilaian) tersebut adalah bagaimana pengelolaan aset negara pada setiap pengguna barang menjadi lebih akuntabel dan transparan. Harapan yang ingin dicapai yaitu aset-aset negara mampu dioptimalkan penggunaan dan pemanfaatannya untuk menunjang fungsi pelayanan kepada masyarakat atau stake-holder. Koridor pengelolaan aset negara memberikan acuan bahwa aset negara harus digunakan semaksimal mungkin untuk mendukung kelancaran tugas pokok dan fungsi pelayanan, dan dimungkinkannya fungsi budgeter dalam pemanfaatan aset untuk memberikan kontribusi penerimaan bagi negara. Penanganan aset negara seperti paparan di atas, yang mengikuti kaidah-kaidah tata kelola yang baik atau good governance akan menjadi salah satu modal dasar yang penting dalam penyusunan Laporan Keuangan Pemerintah Pusat (LKPP) yang akuntabel.

Tabel I.2 Daftar Barang Milik Negara pada Kantor Kementerian Agama Kabupaten Wonogiri

\begin{tabular}{|c|l|c|}
\hline No & \multicolumn{1}{|c|}{ Nama Aset (Barang Milik Negara) } & Keterangan \\
\hline 1 & Tanah & Kantor, KUA, Madrasah \\
\hline 2 & Gedung dan Bangunan & Kantor, KUA, Madrasah \\
\hline 3 & Peralatan dan Mesin & Alat kantor, operasional \\
\hline 4 & Aset Tetap Lainnya & \\
\hline 5 & Konstruksi dalam Pengerjaan & Persediaan,diserahkan masyarakat \\
\hline 6 & Belanja Barang dan Jasa & \\
\hline
\end{tabular}

Sumber: Kantor Kementerian Agama Kabupaten Wonogiri Tahun 2017 
Upaya Efisiensi pengelolaan aset negara antara lain diawali dengan penyusunan Roadmap Strategic Assets Management, oleh Direktorat Jenderal Kekayaan Negara (DJKN). Tujuan akhir yang ingin dicapai dari roadmap ini adalah terciptanya Strategic Assets Management (SAM) dengan ultimate goal-nya, dimana aset negara menjadi indikator penting dalam pelaksanaan anggaran yang efektif. Roadmap yang dibuat DJKN) selaku pengelola kekayaan negara menjadi fondasi untuk melengkapi atribut organisasi dan memulainya penertiban BMN. DJKN kemudian melakukan penyempurnaan Sistem Pengendalian Internal dan tata kelola pengelolaan aset, serta penatausahaan yang andal dan akuntabel.

Dalam Roadmap Strategic Assets Management tersebut, DJKN berupaya untuk melakukan integrasi perencanaan dan penganggaran aset negara dan optimalisasi pengelolaan aset negara (the highest and the best use). Pertanggungjawaban atas Barang Milik Negara kemudian menjadi semakin penting ketika pemerintah wajib menyampaikan pertanggungjawaban atas pelaksanaan APBN dalam bentuk laporan keuangan yang disusun melalui suatu proses akuntansi atas transaksi keuangan, aset, hutang, ekuitas dana, pendapatan dan belanja, termasuk transaksi pembiayaan dan perhitungan. Informasi Barang Milik Negara memberikan sumbangan yang signifikan di dalam laporan keuangan (neraca) yang berkaitan dengan pos-pos persediaan, aset tetap, maupun aset lainnya. Peran Strategic Assets Management (SAM) dengan demikian menjadi penting.

Manajemen strategis hadir sebagai seni dan ilmu penyusunan, penerapan, dan pengevaluasian keputusan-keputusan lintas fungsional yang dapat memungkinkan suatu organisasi atau perusahaan mencapai sasarannya (David, 2011). Manajemen strategis dibangun sebagai proses untuk penetapan tujuan organisasi, pengembangan kebijakan, dan perencanaan untuk mencapai tujuan organisasi, serta mengalokasikan sumber daya untuk menerapkan pencapaian tujuan organisasi tersebut. Manajemen strategis mengkombinasikan aktivitas-aktivitas dari berbagai bagian fungsional organisasi untuk mencapai tujuan organisasi atau perusahaan. Manajemen strategis adalah proses untuk membantu organisasi dalam mengidentifikasi apa yang ingin mereka capai, dan bagaimana seharusnya mereka mencapai hasil yang bernilai.
Pengelolaan aset negara akan disertai dengan pengamanan fisik, pengamanan administratif, dan pengamanan hukum. Dalam rangka pengamanan administratif dibutuhkan sistem penatausahaan yang dapat menciptakan pengendalian (controlling) atas Barang Milik Negara. Sistem penatausahaan tersebut selain berfungsi sebagai alat kontrol juga harus dapat memenuhi kebutuhan manajemen pemerintah di dalam perencanaan pengadaan, pengembangan, pemeliharaan, maupun penghapusan (disposal).

Kantor Kementerian Agama Kabupaten Wonogiri sebagai instansi vertikal Kementerian Agama berupaya mengelola asetnya untuk mendukung kelancaran tugas pokok dan fungsi pelayanan, dan dimungkinkannya fungsi budgeter dalam pemanfaatan aset untuk memberikan kontribusi penerimaan bagi negara. Secara umum, pengelolaan aset negara tersebut meliputi aktivitas inti yaitu perencanaan (planning), perolehan (acquisition), pemanfaatan (utilization), dan penghapusan (disposal).

Pengelolaan aset negara diharapkan mampu memberikan gambaran kondisi sekarang berapa besar nilai seluruh aset negara, baik itu yang bersumber dari APBN maupun dari sumber perolehan lainnya yang sah. Ketersediaan database BMN yang komprehensif dan akurat pun dapat segera terwujud. Database BMN akan memainkan peran yang strategis dalam setiap pengambilan keputusan perencanaan kebutuhan barang nasional oleh Pengelola Barang dan usulan alokasi penganggarannya dalam APBN. Hal ini akan menimbulkan hubungan sinergis antara perencana anggaran dengan pengelola barang untuk merumuskan dan menentukan besaran rencana kebutuhan barang milik negara dalam tahun anggaran. Harapannya bahwa anggaran belanja modal fisik tersebut dapat lebih dipertanggungjawabkan dan benar-benar mencerminkan kebutuhan barang atau aset yang nyata sesuai kondisi di lapangan dan mampu menciptakan anggaran belanja modal yang efektif, efisien, dan tepat sasaran, tidak hanya bersifat incremental.

Permasalahan dalam pengelolaan aset terkait manajemen strategis pada Kantor Kementerian Agama Kabupaten Wonogiri bahwa dalam pengelolaan aset; penyusunan anggaran belum secara komprehensif mengakomodir pengelolaan aset. Sebagai misal untuk penghapusan atas aset-aset yang sudah tidak layak pakai belum diprogramkan dan dianggarkan. Pensertifikatan tanah sebagai bagian dari langkah penetapan status 
kepemilikan atas aset belum diakomodir. Padahal dari anggaran akan tergambar kegiatan-kegiatan yang akan dilaksanakan beserta alokasi dana yang disediakan. Hasil akhir dari suatu anggaran adalah pernyataan-pernyataan tentang pengeluaran dan pendapatan yang diharapkan dari setiap sumber pembiayaan.

Permasalahan berikutnya terkait implementasi strategi, bahwa aturan atau teknik pelaksanaan sistem tahap demi tahap untuk melaksanakan suatu aktivitas belum semuanya disusun. Prosedur atau yang lebih dikenal dengan Standard Operating Procedure) (SOP) terkait pengelolaan aset misalnya: prosedur terhadap perencanaan atau kebutuhan aset, prosedur perolehan aset, prosedur penatausahaan aset, dan sebagainya. Kenyataan yang ada pada Kantor Kemententerian Agama Kabupaten Wonogiri belum membuat prosedur-prosedur tersebut sebagaimana mestinya.

Permasalahan berikutnya bahwa implementasi pengelolaan aset tingkat akurasi aset yang dikelola masih rendah. Akurasi aset seharusnya tertib pencatatan dan penilaian harus dimulai sejak dari tahap pengadaan. Pada tahap pengadaan, detail spesifikasi dari aset harus dirinci dengan jelas, baik untuk aset bergerak maupun aset tidak bergerak. Hal ini menjadi penting dan berpengaruh untuk proses dilakukan rekonsiliasi. Penilaian dan rekonsiliasi ini perlu dilakukan agar dapat diketahui nilai wajar sesungguhnya dari nilai aset yang bersangkutan. Permasalahan yang selama ini juga dihadapi yaitu pihak pengelola barang milik negara kurang memiliki komitmen mengenai penilaian dan rekonsiliasi. Padahal dengan rekonsiliasi dapat diketahui kesesuaian antara nilai aset dengan nilai wajar, sehingga akan diketahui apakah aset tersebut perlu dilakukan penilaian ulang atau tidak. Apalagi rekonsiliasi ini menjadi salah satu komponen yang menjadi obyek pemeriksaan dari instansi pemeriksa (Inspektorat Jenderal, Badan Pengawasan Keuangan dan Pembangunan (BPKP), Badan Pemeriksa Keuangan Republik Indonesia (BPKRI). Adanya temuan instansi pemeriksa ini akan bermuara pada penilaian Laporan Keuangan Kementerian atau Lembaga.

Tabel 1.4 Rincian Aset Tetap Per 31 Desember 2017 dan 31 Desember 2016

\begin{tabular}{|c|l|c|r|c|}
\hline NO & \multicolumn{1}{|c|}{ Aset Tetap } & \multicolumn{1}{c|}{$\begin{array}{c}\text { Nilai } \\
\text { Perolehan }\end{array}$} & $\begin{array}{c}\text { Akumulasi } \\
\text { Penyusutan }\end{array}$ & Nilai Buku \\
\hline 1 & $\begin{array}{l}\text { Peralatan dan } \\
\text { Mesin }\end{array}$ & 1.036 .231 .850 & $(956.299 .435)$ & 79.932 .415 \\
\hline 2 & $\begin{array}{l}\text { Gedung dan } \\
\text { Bangunan }\end{array}$ & 6.194 .527 .500 & $(851.939 .324)$ & 5.342 .588 .176 \\
\hline 3 & $\begin{array}{l}\text { Jalan, Irigasi } \\
\text { Bangunan }\end{array}$ & - & & - \\
\hline 4 & $\begin{array}{l}\text { Aset Tetap } \\
\text { Lainnya }\end{array}$ & 85.498 .000 & $(85.498 .000)$ & 170.996 .000 \\
\hline Akumulasi Penyusutan & $\mathbf{7 . 3 1 6 . 2 5 7 . 3 5 0}$ & $\mathbf{( 1 . 8 9 3 . 7 3 6 . 7 5 9 )}$ & $\mathbf{5 . 5 9 3 . 5 1 6 . 5 9 1}$ \\
\hline
\end{tabular}

Sumber:Catatan Atas Laporan Keuangan Semester 2 Tahun 2017

Berikutnya terkait pengawasan, masih belum jelasnya beberapa status aset yang dikelola oleh Kantor Kementerian Agama Kabupaten Wonogiri. Aset berupa tanah, kendaraan, maupun peralatan dan mesin belum memiliki penetapan status. Hal ini bisa menjadi masalah oleh karena bisa dimungkinkan menimbulkan sengketa. Penetapan status ini juga menjadi penting terkait ketika nantinya akan dilakukan pemeliharaan atau bahkan penghapusan pada aset negara tersebut. Selanjutnya sering terjadi tidak tertibnya dalam hal penguasaan aset, terutama untuk aset dalam penguasaan pejabat yang purna tugas, yang hal ini dikarenakan kurang tegasnya dari pihak pengelola aset untuk menarik kembali aset yang telah selesai dalam masa pakai. 
Daftar BMN

Yang Belum Memperoleh Penetapan Status Kepemilikan

\begin{tabular}{|l|l|c|c|c|c|c|}
\hline \multirow{2}{*}{ NO } & \multirow{2}{*}{ JENIS BARANG } & \multirow{2}{*}{ NUP BARU } & \multicolumn{2}{|c|}{ PEROLEHAN } & \multicolumn{2}{|c|}{ NILAI/HARGA } \\
\cline { 5 - 7 } & & & TH & ASAL & PEROLEHAN & $\begin{array}{c}\text { APLIKASI } \\
\text { SIMAK }\end{array}$ \\
\hline 1 & $\begin{array}{l}\text { Tanah Bangunan } \\
\text { Kantor Kemenag } \\
\text { Wonogiri }\end{array}$ & 1 & 1993 & APBN & 392.000 .000 & 921.200 .000 \\
\hline 2 & $\begin{array}{l}\text { Tanah Bangunan } \\
\text { Kantor KUA }\end{array}$ & $1-5$ & 1990 & APBN & 165.894 .000 & 2.104 .229 .000 \\
\hline 3 & Kemenag Wonogiri & 1 & 1993 & APBN & 47.000 .000 & 649.715 .000 \\
\hline 4 & $\begin{array}{l}\text { Bangunan gudang } \\
\text { tertutup }\end{array}$ & 1 & 1980 & APBN & & 28.593 .000 \\
\hline 5 & $\begin{array}{l}\text { Bangunan tempat } \\
\text { ibadah }\end{array}$ & 1 & 1980 & APBN & & 51.669 .000 \\
\hline 6 & $\begin{array}{l}\text { Rumdin Gol II , Type } \\
\text { C }\end{array}$ & 1 & 1980 & APBN & & 83.540 .000 \\
\hline 7 & $\begin{array}{l}\text { Rumdin Gol II , Type } \\
\text { C }\end{array}$ & 2 & 1980 & APBN & & 42.984 .000 \\
\hline 8 & KUA & $2-27$ & 1979 & APBN & 479.543 .880 & 4.170 .541 .000 \\
\hline 9 & $\begin{array}{l}\text { Bangunan } \\
\text { t.pertemuan }\end{array}$ & 1 & 1979 & APBN & 38.000 .000 & 1.016 .514 .000 \\
\hline 10 & Kendaraan & $1-42$ & $\begin{array}{l}1997- \\
2010\end{array}$ & APBN & 528.835 .000 & 528.835 .000 \\
\hline 11 & Inventaris & 1155 & $2001-$ & APBN & 793.914 .450 & 793.914 .450 \\
\hline
\end{tabular}

Masalah-masalah tersebut tentu saja terkait dengan kepemimpinan dan komitmen dari pegawai yang dilakukan terhadap pengelolaan aset pada Kantor Kementerian Agama Kabupaten Wonogiri. Pimpinan puncak melalui manajemen strategis, harus mampu merumuskan dan menentukan strategi organisasi yang tepat dalam pengelolaan asetnya sehingga organisasi yang bersangkutan optimal dalam pengelolaan asetnya. Pimpinan memiliki ketangguhan untuk melakukan penyesuaian dan perubahan yang diperlukan sehingga organisasi atau lembaga tersebut semakin meningkat efektif dan akuntabel. Fungsi kepemimpinan ini menjadi fungsi kontrol dalam pengelolaan aset. Hasil penelitian yang dilakukan Supriyadi (2016) membuktikan kepemimpinan berpengaruh terhadap pengelolaan aset.

Berdasarkan pendekatan manajemen strategis, pimpinan pada semua tingkatan organisasi berinteraksi dalam perencanaan dan implementasi strategi. Ini merupakan wujud komitmen mereka kepada organisasi. Akhirnya komitmen organisasi menjadi konsekuensi perilaku manajemen strategis serupa dengan pengambilan keputusan partisipatif (Pearce dan Robinson, 2008:13.

Komitmen organisasi akan mengarah pada pembentukan strategi. Manajemen strategi merupakan hal yang sangat penting dalam kegiatan pengelolaan aset. Seperti yang dikemukakan Bernardz ( Maharani 2012 hal 17) bahwa Strategic Assets Management (SAM) adalah suatu model baru untuk mengekstraksi nilai dari aset-aset produksi. Konsep dasar SAM adalah penggunaan sumber daya secara total untuk keunggulan berkompetisi. Pengembangan sistem dan proses ini guna mendukung penyusunan strategi organisasi yang meliputi pengadaan, pemeliharaan, perbaikan, alokasi, dan penghapusan, secara bersamaan diperlukan kepemimpinan dan pendekatan terintegrasi terhadap perencanaan dan manajemen aset memungkinkan entitas untuk memberikan pelayanan berbasis aset yang berkualitas secara efisien dan efektif dengan dukungan komitmen organisasi. Hasil penelitian yang dilakukan Rosihan (2014) membuktikan bahwa komitmen organisasi berpengaruh terhadap pengelolaan aset.

Setiap aset yang dimiliki haruslah dikelola dengan efektif dan efisien atau biasa dikenal dengan manajemen strategis terhadap aset. Manajemen aset ini dilakukan agar aset tersebut dapat memberikan manfaat tertinggi bagi kementerian atau lembaga karena aset merupakan bagian yang penting dalam pencapaian tujuan dari pemilik aset, di mana aset terletak di dalam bagian dari proses yang membantu dalam pencapaian tujuan sebelum 
nantinya menjadi output yang diharapkan (goals).

Kantor Kementerian Agama Kabupaten Wonogiri melalui proses management planning, implementation, leading dan controlling bertujuan pengeluaran yang dilakukan efisien dan efektif. Pengelolaan aset agar dapat dikelola dengan baik, Kantor Kementerian Agama Kabupaten Wonogiri harus mengevaluasi

\section{METODE}

Jenis penelitian ini adalah kuantitatif dengan level eksplanatif yang menjelaskan hubungan sebab akibat dari variabel penelitian. Data yang digunakan adalah data primer dengan mengambil sampel secara sensus sebanyak 50 (lima puluh) responden. Penelitian ini menggunakan alat analisis berupa uji validitas, uji reliabilitas, uji linieritas, analisa jalur, analisa regresi linier berganda, uji t, uji $\mathrm{F}$ dan koefisien determinasi.

Analisis regresi jalur adalah, analisis jalur merupakan pengembangan langsung bentuk regresi berganda dengan tujuan untuk memberikan estimasi tingkat kepentingan

$Y_{1}=\alpha+\beta_{1} X_{1}+\beta_{2} X_{2}+\varepsilon \quad$ (Persamaan I)

$Y_{2}=\alpha+\beta_{1} X_{1}+\beta_{2} X_{2}+\beta_{3} X_{3}+\beta_{4} Y_{1}+\varepsilon$ (Persamaan II)

\section{HASIL PENELITIAN}

Tabel.1. Hasil Analis Jalur Persamaan 1

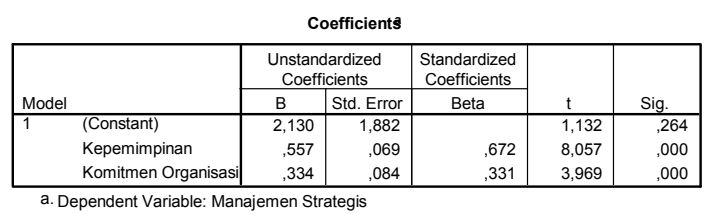

Tabel. 2. Hasil Analis Jalur Persamaan 2

\begin{tabular}{|c|c|c|c|c|c|c|}
\hline \multicolumn{7}{|c|}{ Coefficients } \\
\hline \multirow[b]{2}{*}{ Model } & & \multicolumn{2}{|c|}{$\begin{array}{l}\text { Unstandardized } \\
\text { Coefficients }\end{array}$} & \multirow{2}{*}{$\begin{array}{c}\text { Standardized } \\
\text { Coefficients }\end{array}$} & \multirow[b]{2}{*}{$t$} & \multirow[b]{2}{*}{ Sig. } \\
\hline & & $B$ & Std. Error & & & \\
\hline 1 & (Constant) & 11,478 & 1,978 & & 5,803 & .000 \\
\hline & Kepemimpinan &, 266 & 111 & 295 & 2,400 & ,020 \\
\hline & Komitmen Organisasi & 240 & 101 & 219 & 2,379 &, 022 \\
\hline & Manajemen Strategis &, 518 & 151 & ,477 & 3,427 & ,001 \\
\hline
\end{tabular}

Tabel.3. Hasil Uji F Persamaan 1

\begin{tabular}{|c|c|c|c|c|c|c|}
\hline \multicolumn{7}{|c|}{ ANOVR } \\
\hline Model & & $\begin{array}{c}\text { Sum of } \\
\text { Squares }\end{array}$ & df & Mean Square & $\mathrm{F}$ & Sig. \\
\hline \multirow[t]{3}{*}{1} & Regression & 146,704 & 2 & 73,352 & 57,291 &, $000^{\mathrm{a}}$ \\
\hline & Residual & 60,176 & 47 & 1,280 & & \\
\hline & Total & 206,880 & 49 & & & \\
\hline
\end{tabular}

masalah-masalah diatas, dan untuk hal tersebut diperlukan kajian terhadap implementasi manajemen strategis pada pengelolaan aset negara. Berdasarkan uraian di atas maka perlu diteliti: Implementasi Manajemen Strategis dalam Pengelolaan Aset Negara: Studi Empiris pada Kantor Kementerian Agama Kabupaten Wonogiri.

(magnitude) dan signifikasi (significance) hubungan sebab akibat hipotetikal dalam seperangkat variabel.

Hubungan kausalitas akan digunakan analisis jalur dan intervening. Pada penelitian ini manajemen strategis ditempatkan sebagai variabel intervening untuk variabel kepemimpinan, komitmen organisasi terhadap pengelolaan aset.

Analisis regresi linear berganda digunakan untuk menganalisa pengaruh beberapa variabel bebas atau independen variabel (X) terhadap satu variabel tidak bebas atau dependen variabel (Y) sebagai berikut:.

$$
\text { II) }
$$

Tabel.4. Hasil Uji F Persamaan 2

\begin{tabular}{|c|c|c|c|c|c|c|}
\hline \multicolumn{7}{|c|}{ ANOVAP } \\
\hline Model & & $\begin{array}{l}\text { Sum of } \\
\text { Squares }\end{array}$ & df & Mean Square & $\mathrm{F}$ & \\
\hline 1 & Regression & 180,879 & 3 & 60,293 & 43,814 &, $000^{\mathrm{a}}$ \\
\hline & Residual & 63,301 & 46 & 1,376 & & \\
\hline & Total & 244,180 & 49 & & & \\
\hline
\end{tabular}

a. Predictors: (Constant), Manajemen Strategis, Komitmen Organisasi, Kepemimpinan

b. Dependent Variable: Pengelolaan Aset

Tabel.5. Koefisien Determinan $\left(\mathrm{R}^{2}\right)$ Persamaan 1

\begin{tabular}{|c|c|c|c|c|}
\hline \multicolumn{5}{|c|}{ Model Summary } \\
\hline Model & $\mathrm{R}$ & R Square & $\begin{array}{l}\text { Adjusted } \\
\text { R Square }\end{array}$ & $\begin{array}{l}\text { Std. Error of } \\
\text { the Estimate }\end{array}$ \\
\hline 1 &, $842^{\mathrm{a}}$ &, 709 & 697 & 1,132 \\
\hline
\end{tabular}

Tabel.6. Koefisien Determinan $\left(\mathrm{R}^{2}\right)$ Persamaan 2

\begin{tabular}{|l|r|r|r|r|}
\hline Model & $\mathrm{R}$ & R Square & $\begin{array}{c}\text { Adjusted } \\
\text { R Square }\end{array}$ & $\begin{array}{c}\text { Std. Error of } \\
\text { the Estimate }\end{array}$ \\
\hline 1 &, $861^{\mathrm{a}}$ &, 741 &, 724 & 1,173 \\
\hline
\end{tabular}
a. Predictors: (Constant), Manajemen Strategis,
Komitmen Organisasi, Kepemimpinan
b. Dependent Variable: Pengelolaan Aset


Tabel.7. Koefisien Korelasi

\begin{tabular}{|c|c|c|c|c|c|}
\hline \multicolumn{6}{|c|}{ Correlations } \\
\hline & & $\begin{array}{c}\text { Kepemim } \\
\text { pinan }\end{array}$ & $\begin{array}{l}\text { Komitmen } \\
\text { Organisasi }\end{array}$ & $\begin{array}{c}\text { Manajemen } \\
\text { Strategis }\end{array}$ & $\begin{array}{c}\text { Pengelolaan } \\
\text { Aset }\end{array}$ \\
\hline \multirow[t]{3}{*}{ Kepemimpinan } & Pearson Correlation & 1 &, $332^{*}$ & , $782^{* *}$ &., $741^{\prime \prime}$ \\
\hline & Sig. (2-tailed) & &, 018 & ,000 & ,000 \\
\hline & $\mathrm{N}$ & 50 & 50 & 50 & 50 \\
\hline \multirow[t]{3}{*}{ Komitmen Organisasi } & Pearson Correlation &, $332^{*}$ & 1 &, $554^{* *}$ &, $581^{\circ}$ \\
\hline & Sig. (2-tailed) & ,018 & & ,000 &, 000 \\
\hline & $\mathrm{N}$ & 50 & 50 & 50 & 50 \\
\hline \multirow[t]{3}{*}{\begin{tabular}{|l} 
Manajemen Strategis \\
\end{tabular}} & Pearson Correlation &, $782^{* *}$ &, $554^{*}$ & 1 &, $829^{*}$ \\
\hline & Sig. (2-tailed) & ,000 &, 000 & &, 000 \\
\hline & $\mathrm{N}$ & 50 & 50 & 50 & 50 \\
\hline \multirow[t]{3}{*}{ Pengelolaan Aset } & Pearson Correlation &, $741^{* *}$ &, $581^{*}$ & $829^{*}$ & 1 \\
\hline & Sig. (2-tailed) &, 000 & ,000 & ,000 & \\
\hline & $\mathrm{N}$ & 50 & 50 & 50 & 50 \\
\hline
\end{tabular}

Persamaan 2 yaitu:

$$
\begin{array}{lll}
\mathrm{Y}_{2} & = & 0,295 \mathrm{X}_{1} \\
\mathrm{Sig} & (0,020)^{* *} & 0,219 \mathrm{X}_{2}+0,477 \mathrm{X}_{3}+\epsilon_{2} \\
\mathrm{Sin} & (0,022)^{* *} & (0,001)^{* *}
\end{array}
$$

Berdasarkan hasil analisa jalur dapat diperoleh hasil sbb:

Persamaan 1 yaitu :

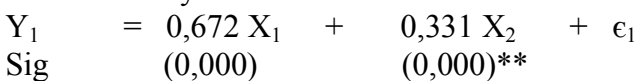

Model Hasil Analisis

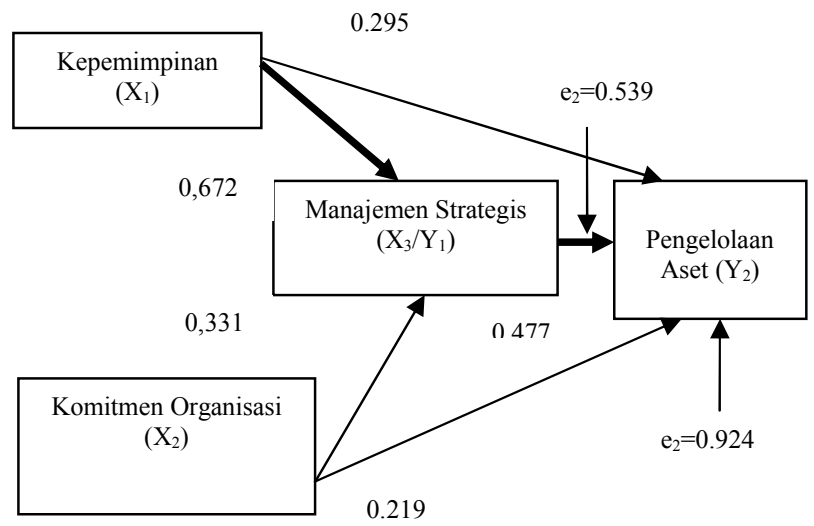

\section{PEMBAHASAN}

1. Berdasarkan hasil analisis jalur, pengaruh tidak langsung kepemimpinan terhadap pengelolaan aset melalui manajemen strategis di Kantor Kementerian Agama Kabupaten Wonogiri adalah positif signifikan. Artinya apabila semakin baik tingkat kepemimpinan melalui manajemen strategis, maka semakin baik pula pengelolaan aset di Kantor Kementerian Agama Kabupaten Wonogiri. Hasil penelitian ini mendukung teori yang dikemukan bahwa kepemimpinan menciptakan suatu sistem evaluasi yang mengevaluasi strategi di setiap tahap kerja dalam organisasi. Akhirnya itu membantu mengubah budaya yang memfasilitasi strategis manajemen (Venohr, 2007). Hasil penelitian ini mendukung penelitian yang dilakukan Widodo dan Setyorini (2014), dan Bukhari (2017) yang menyatakan bahwa kepemimpinan mempunyai pengaruh terhadap pengelolaan aset melalui manajemen strategis. Berdasarkan indikator yang digunakan pada variabel kepemimpinan yang menonjol yaitu, nilai $\mathrm{r}_{\text {hitung }}$ terletak pada item pertanyaan: pimpinan memberikan kesempatan kepada pegawai untuk berpendapat $\left(\mathrm{X}_{1} .1\right)$, pimpinan memberikan contoh yang baik kepada pegawai $\left(\mathrm{X}_{1} .5\right)$, pimpinan memberikan bimbingan, dorongan, dan pengarahan kepada pegawai $\left(\mathrm{X}_{1} .2\right)$.

Maka diperlukan upaya untuk meningkatkan perbaikan pengelolaan aset dengan menggunakan pengaruh tidak langsung manajemen strategis untuk perbaikan pengelolaan aset. Peningkatan perilaku kepemimpinan untuk meningkatkan perbaikan pengelolaan aset secara konkrit melalui manajemen strategis dilakukan dengan:

a) Pimpinan memberikan kesempatan kepada pegawai untuk berpendapat terhadap perbaikan pengelolaan asetnya melalui rapat koordinasi secara periodik maupun ketika dilakukan monitoring dan evaluasi atas kondisi aset yang dikelola sehingga 
terjalin komunikasi, koordinasi, dan sinergi dalam pengelolaan aset.

b) Pimpinan dapat menberikan contoh yang baik terhadap pengelolaan aset, misaknya turut serta dan berpartisipasi dalam kegiatan sosialisasi dan pembinaan pengelolaan aset negara, turut serta mengamankan dan memelihara aset yang digunakan, menarik kembali aset yang telah selesai dalam masa pakai.

c) Pimpinan memberikan bimbingan, dorongan, dan arahan dalam pengelolaan aset yang dapat dilakukan melalui kegiatan rapat, monitoring, dan evaluasi dalam pengelolaan aset.

2. Berdasarkan hasil analisis jalur diketahui pengaruh langsung komitmen organisasi terhadap pengelolaan aset adalah positif dan signifikan. Artinya komitmen organisasi mempengaruhi pengelolaan aset pada Kantor Kementerian Agama Kabupaten Wonogiri. Hasil analisis jalur juga menunjukkan bahwa pengaruh langsung lebih efektif dibandingkan pengaruh tidak langsung.

Hasil penelitian ini mendukung teori yang dikemukan bahwa komitmen mencakup juga keterlibatan kerja dalam organisasi. Keterlibatan kerja sebagai derajat kemauan untuk menyatukan dirinya dengan pekerjaan, menginvestasikan waktu, kemampuan dan energinya untuk pekerjaan, dan menganggap pekerjaannya sebagai bagian utama dari kehidupannya. Cater, (2010: 2 dalam Mufarrohah, dkk 2013) Temuan ini mendukung hasil penelitian yang dlakukan oleh Rosihan (2014), Erizul dan Yuliani (2014), bahwa komitmen organisasi berpengaruh signifikan terhadap pengelolaan aset. Peningkatan komitmen organisasi dapat memperbaiki pengelolaan aset secara konkrit dilakukan dengan melihat Berdasarkan indikator yang digunakan pada variabel komitmen organisasi yang menonjol yaitu, nilai $\mathrm{r}_{\text {hitung }}$ terletak pada item pertanyaan: organisasi terlibat secara langsung dalam pengelolaan aset negara $\left(\mathrm{X}_{2} .2\right)$, pegawai merasa bangga dengan menjadi bagian pada organisasi $\left(\mathrm{X}_{2} .1\right)$, pegawai sadar bahwa komitmen pengelolaan aset adalah hal yang turut menjadi tugas pegawai $\left(\mathrm{X}_{2} .4\right)$.

Dari hasil tersebut maka langkah konkrit yang direkomendasikan kepada pegawai pada Kantor Kementerian Agama Kabupaten Wonogiri terlibat langsung dalam pengelolaan aset yang dikelola yaitu: a) Turut serta mengamankan dan memelihara aset yang berada dalam ruang, mengembalikan ketika mutasi pegawai dilakukan atau ketika purna tugas.

b) Pegawai pada Kantor Kementerian Agama Kabupaten Wonogiri merasakan kebanggaan sebagai bagian dari organisasi sehingga memiliki kewajiban dan tanggung jawab untuk turut serta dalam pengelolaan asetnya.

c) Pegawai pada Kantor Kementerian Agama Kabupaten Wonogiri memaknai dan menyadari bahwa pengelolaan aset negara merupakan bagian dari komitmen mereka sebagai pegawai pada Kantor Kementerian Agama Kabupaten Wonogiri.

3. Upaya-upaya pengelolaan aset negara pada Kantor Kementerian Agama Kabupaten Wonogiri diharapkan akan berakibat pada perilaku pimpinan terkait strategi-strategi yang dapat dilakukan pada pengelolaan aset dan juga menumbuhkan komitmen dari pegawai yang nantinya berdampak pada peningkatan perbaikan pada pengelolaan aset pada Kantor Kementerian Agama Kabupaten Wonogiri. Berdasarkan indikator yang digunakan pada variabel manajemen strategis yang menonjol yaitu, nilai $r_{\text {hitung }}$ terletak pada item pertanyaan: Organisasi telah melakukan proses/tahap rekonsiliasi pengelolaan aset sesuai aturan dan prosedur $\left(\mathrm{X}_{3} .4\right)$, Organisasi telah melakukan perencanaan atau perkiraan mengenai besarnya anggaran dalam kegiatan pengelolaan aset $\left(\mathrm{X}_{3} .2\right)$, Organisasi ini telah melakukan strategi-strategi tertentu dalam kegiatan pengelolaan aset $\left(\mathrm{X}_{3} .1\right)$. Dari hasil tersebut maka langkah konkrit yang direkomendasikan terhadap pengelolaan aset pada Kantor Kementerian Agama Kabupaten Wonogiri yaitu:

a) Kantor Kementerian Agama Kabupaten Wonogiri melakukan tahap atau proses rekonsiliasi pengelolaan aset sesuai aturan dan prosedur. Pelaksanaan rekonsiliasi dilakukan secara periodik (bulanan dan semesteran) dengan tertib pencatatan sehingga tidak lagi ditemukan peralatan, mesin, persediaan, gedung dan bangunan yang masih belum diregister.

b) Kantor Kementerian Agama Kabupaten Wonogiri melakukan perencanaan atau perkiraan mengenai besarnya anggaran dalam Daftar Isian Pelaksanaan Anggaran untuk selanjutnya dapat disusun Rencana Anggaran Biaya dalam kegiatan tahun 
anggaran sebagai kebijakan dalam pengelolaan aset.

c) Kantor Kementerian Agama Kabupaten Wonogiri melakukan strategi-strategi tertentu dalam kegiatan pengelolaan aset yaitu bahwa pengelolaan aset merupakan kegiatan prioritas dalam tahun anggaran, dengan penganalisaan kebutuhan akan aset, yang diimplementasikan dalam detail kegiatan seperti pemutkhiran aset yang dikelola, upaya penetapan status terhadap aset-aset yang dimiliki dan dikelola, penghapusan atas aset yang sudah tidak layak guna dan tidak layak pakai.

\section{PENUTUP}

\section{Simpulan}

1. Hasil dalam penelitian ini menunjukkan bahwa:

a. Kepemimpinan berpengaruh positif dan signifikan terhadap manajemen strategis di Kantor Kementerian Agama Kabupaten Wonogiri, atau Hipotesis $1\left(\mathrm{H}_{1}\right)$ terbukti

b. Komitmen organisasi berpengaruh positif dan signifikan terhadap manajemen strategis di Kantor Kementerian Agama Kabupaten Wonogiri., atau Hipotesis 2 $\left(\mathrm{H}_{2}\right)$ terbukti.

c. Kepemimpinan berpengaruh positif dan signifikan terhadap pengelolaan aset negara di Kantor Kementerian Agama Kabupaten Wonogiri, atau Hipotesis 3 $\left(\mathrm{H}_{3}\right)$ terbukti.

d. Komitmen Organisasi berpengaruh positif dan signifikan terhadap pengelolaan aset negara di Kantor Kementerian Agama Kabupaten Wonogiri, atau Hipotesis 4 $\left(\mathrm{H}_{4}\right)$ terbukti.

e. Manajemen strategis berpengaruh positif dan signifikan terhadap pengelolaan aset negara di Kantor Kementerian Agama Kabupaten Wonogiri, atau Hipotesis 5 $\left(\mathrm{H}_{5}\right)$ terbukti.

2. Hasil uji dapat disimpulkan secara bersamasama variabel kepemimpinan, komitmen organisasi, dan manajemen strategis berpengaruh signifikan terhadap pengelolaan aset negara pada Kantor Kementerian Agama Kabupaten Wonogiri.

3. Nilai $\left(\mathrm{R}^{2}\right)$ total sebesar 0,924 dapat diartikan variabel pengelolaan aset Kantor Kementerian Agama Kabupaten Wonogiri dijelaskan oleh variabel kepemimpinan, komitmen organisasi, dan manajemen strategis sebesar 92\% dan sisanya sebesar $8 \%$ dijelaskan variabel .lain di luar model penelitian.
4. Hasil analisis jalur menunjukkan bahwa:

a. Jalur tidak langsung kepemimpinan terhadap pengelolaan aset melalui manajemen strategis merupakan jalur yang dominan dan efektif dalam pengelolaan aset. Artinya variabel manajemen strategis merupakan variabel mediasi bagi variabel kepemimpinan.

b. Komitmen organisasi lebih efektif melalui jalur langsung, karena hasil pengaruh langsung lebih besar daripada pengaruh tidak langsung. Artinya variabel manajemen strategis bukan merupakan variabel mediasi bagi variabel komitmen organisasi.

\section{Saran}

Berdasarkan hasil kesimpulan seperti di atas maka peneliti memberi beberapa saran sebagai berikut:

1. Sebaiknya kepemimpinan melalui manajemen strategis dapat diimplementasikan, oleh karena kepemimpinan melalui variabel manajemen strategis merupakan variabel paling dominan atau efektif dalam pengelolaan aset. Cara-cara yang dapat dilakukan diantaranya dengan:

a. Kantor Kementerian Agama Kabupaten Wonogiri melalui otoritas pimpinan, untuk senantiasa dapat melakukan tahap atau proses rekonsiliasi pengelolaan aset sesuai aturan dan prosedur, oleh karena rekonsiliasi menjadi salah satu komponen yang menentukan dalam penilaian Laporan Keuangan Kementerian atau Lembaga sehingga dapat dilakukan secara periodik (bulanan dan semesteran) dengan tertib pencatatan dan tidak lagi ditemukan peralatan, persediaan, gedung dan bangunan yang masih belum diregister.

b. Kantor Kementerian Agama Kabupaten Wonogiri melaui otoritas pimpinan, melakukan perencanaan atau perkiraan mengenai besarnya anggaran dalam Daftar Isian Pelaksanaan Anggaran (DIPA) untuk selanjutnya dapat disusun Rencana Anggaran Biaya (RAB) terhadap kegiatan pengelolaan aset pada tahun anggaran sebagai salah satu kebijakan dalam pengelolaan aset.

c. Pimpinan puncak pada Kantor Kementerian Agama Kabupaten Wonogiri melalui manajemen strategis harus mampu merumuskan dan menentukan strategistrategi tertentu dalam kegiatan pengelolaan asset yaitu pengelolaan asset 
merupakan kegiatan prioritas dalam tahun anggaran, dengan penganalisaan kebutuhan akan aset, yang diimplementasikan dalam detail kegiatan pemutahiran aset yang dikelola, upaya penetapan stautus terhadap aset yang dimiliki, penghapusan aset yang sudah tidak layak guna dan pakai, monitoring dan pengawasan terhadap aset.yang dimiliki dan dikelola.

\section{DAFTAR PUSTAKA}

Ambar, Teguh, Sulistyani. 2008. Kepemimpinan Profesional; Pendekatan Leadership, Gava Media. Yogyakarta.

Amin, Muh. 2016. Implementasi Manajemen Strategis Kepala Sekolah Menengah Pertama di Kabupaten Serang. Jurnal TARBAWI Volume 2. No.02, Juli Desember

Arikunto, Suharsini.2010. Prosedur Penelitian Suatu Pendekatan Praktek. edisi lima. , 2012. Statistik Untuk Penelitian. Alfabeta. Bandung.

Azhar ,Arooj. Ikram,Sumera. Rashid, Sajjad. dan Saqib, Shahnawaz (2013). The Role of Leadership in Strategy Formulation and Implementation International Journal of Management and Organizational Studies

Bukhari, Anwaar, Wajahat. 2017. Strategy Formulation and Role Leadership. SCIMASS Scientific Journal of Management and Social Sciences VolumeI, Issue

Caldwell, David F; Chatman, Jennifer A dan O' Reilly, Charless. 1990. Building Organizational Commitment: A Multyfirm Study, Journal of Occupational Psychology, 63, 243-261.

Daniylo F, N.H, and Lemer, A, 1998. Asset management for the Public Work Manager Challenges and Strategies, "Findings of the APWA Task Force on Asset Management, American Public Works Association". Kansas City: MO

David, F, R. 2011. Strategic Management: Manajemen Strategi Konsep, Edisi 12. Jakarta: Salemba Empat

El-Akruti, K.O, Dwight, R.Zhang. T. 2013. The Strategic Role of Enggeenering Asset Management. International Journal of Production Economics. 146(1). 227-239.

Govindrayan dan Anthony, R.N, 2005. Sistem Pengelolaan Manajemen, Salemba Empat, Jakarta
Galpin, T.J. dan Murray. 1997. Connect Human Resource Strategy to the Bussiness Plan. Human Resource Magazine, March,

Hambali.2010. Inventarisasi Barang Milik Negara. Bandung: Politeknik Negeri Bandung.

Halim, Rahmawati, 2012. Pengaruh Komitmen Organisasi dan Kepemimpinan dalam Meningkatkan Keuangan Daerah pada Dinas Pendapatan, Pengelolaan Keuangan Daerah pada Dinas Pendapatan, Pengelolaan Keuangan dan Aset Banggai Kepulauan Riau. Jurnal Academika FISIP Untad,Vol.04.No.01.

Hariyadi, Bambang. 2003. Strategi Manajemen. Malang: Banyumedia Publishing.

Hastings, Nicholas.A.John, 2010. Physical Asset Management. Springer. ISBN.

Hofer, Charles dan Schendel, 1978.Strategy Formulation Analytical Concept. St. Paul Minnesota: West Publicing Company.

Jabbar, Abdulridha, Ali, dan Hussein, Muhammed, Ali. 2015. The Role of Leadership in Strategic Management. International Journal of Research Granthaalayah.

Jamaludin. 2017. Pengaruh Inventarisasi Aset, Legal Audit Aset, dan Penilaian Aset terhadap Optimalisasi Pemanfaatan Aset Tetap (tanah dan Bangunan) Milik Pemerintah Provinsi NTB. Jurnal Sekuritas Manajemen Keuangan Vol.1. No.1Kartono, Kartini. 2011. Pemimpin dan Kepemimpinan Apakah Kepemimpinan Abnormal itu?. Rajawali Press. Jakarta.

Kotler, P. 2014. Marketing Management, 13th Edition, Pearson Education, New Jersey

Kristianto, Djoko. 2007. Peningkatan Kinerja Berbasis pada Komitmen Organisasi dengan Strategi dan Inovasi. Jurnal Ekonomi dan Kewirausahaan Vol 7, No.1:20-26.

Lestari, Andriani . 2016. Pengaruh Kepemimpinan Partisipatif dan Komitmen Organisasi terhadap Efektifitas Implementasi Rencana Stratejik pada Madrasah Aliyah di KAbupaten Sukabumi Jawa Barat. Jurnal Administrasi Pendidikan Vol. XXIII No.1

Luthans, S. Fried. 2015. Organization Behaviors. Mc. Graw Hil. International Book Company. Japan 
Mardiasmo. 2002. Otonomi Daerah dan Manajemen Keuangan Daerah. Yogyakarta: UPP STIM YKPN.

Mulyadi .2001. Akuntansi Manajemen : Konsep, Manfaat, dan Rekayasa. Edisi Ketiga. Jakarta. Salemba Barat.

Northhouse, P.G. 2003. Leadership: Theory and Practise, Third Edition. New Delhi: Response Book

Oliver, Nick. 1990. Reward, Invesment, Alternatives and Organititional Commitment: Empirical Evidence and Theoritical Development. Journal of Occupational Psycology. Vol.63. 19-31.

Pearce II, J.A, dan R.B, Robinson. 2000. Strategic Management: Formulation, Implementation, and Control, Seventh Edition. Malaysia: Mc. Graw-Hill International Edition.

Peraturan Pemerintah Nomor 24 Tahun 2005 tentang Standar Akuntansi Pemerintahan

Peraturan Pemerintah Nomor 6 Tahun 2006 tentang Pengelolaan Barang Milik Negara

Peraturan Pemerintah Republik Indonesia Nomor 27 Tahun 2014 tentang Pengelolaan Barang Milik Negara/Daerah

Pitoyo, Joko, Heru. 2017. Strategi Manajemen Aset dalam Mengelola Aset Negara dalam Kurun Waktu 10 Tahun Kedepan. Jakarta.

Puspitoarum, Ajeng, Monik. 2016. Analisis Pengelolaan Barang Milik Negara (BMN) pada Badan Pusat Statistik (BPS) Kota Makasar. Jurnal Administrative Reform, Vol.4. No.4. Oktober- Desember.

Raharjo, Toto. Susilo dan Nafisah, Durrotun. 2006. Analisis Pengaruh Gaya Kepemimpinan terhadap Kepuasan Kerja, Komitmen Organisasi, dan Kinerja Karyawan 9Studi Empiris pada Departemen Agama Kabupaten Kendal dan Departemen Agama Kota Semarang). Jurnal Studi Manajemen dan Organisasi. Volume 3. Nomor 2.

Rivai, Veithzal dan Ahmad Fawzi Mohd Basri, 2015. Performance Appraisal. PT Raja Grafindo Persada, Jakarta.

Robbin, S.P. 2007. Perilaku Organisasi: Konsep, Kontroversi, Aplikasi. Edisi kedelapan versi Bahasa Indonesia Jilid 1 dan 2. Pressalindo. Jakarta

Schein, E.H. 1991. Organizational Culture and Leadership. San Fransisco:Jossey-Bass Publisher
Siregar, Doli, D. 2004. Manajemen Aset. Jakarta: PT Gramedia

Soleh, Chabib, dan Heru, Rochmansyah, 2010. Pengelolaan Keuangan dan Aset Daerah, Bandung, Fokus Media.

Sopiah. 2008. Perilaku Organisasi. Yogyakarta

Sugiama, A, Gima. 2004. Manajemen Aeet Pariwisata: PelayananBerkualitas agar Wisatawan Puas dan Loyal, edisi Petama. Bandungardaya Intimart

Suharno. 2002. Standar Penilaian Indonesia (SPI), 2007, Mengacu kepada International Valuation Standards (IVS), KPSPI, Jakarta. Peningkatan Profesionalisme Penilai Pemerintah. Jurnal Surve

Supheni, Indriyan dan Wuryani, Sri. (2014) Implementasi Peraturan Pemerintah No.27 Tahun 2014 tentang Pengelolaan Barang Milik Negara pada Pemerintah Daerah Nganjuk. Seminar dan Call Paper disajikan pada Invesment Challenges and Opprtunities In Indonesian Capital Market in The Era of ASEAN Community. Fakultas Ekonomi UNIBA. Surakarta

Supriyadi, Acim dan Hasunah, Nanu. 2016. Peran Kepemimpinan, Pengelolaan Mobil Operasional, Akuntabilitas Aparatur Desa dan Pelayanan Masyarakat Desa. Jurnal Buana Akuntansi ISSN 2528-1119 Vol.1 No.1

Suryana, Asep. 2004. Kepemimpinan Kepala Sekolah dan Kreatifitas Komite Sekolah dalam Membangun Mutu Sekolah dan Value Based Leadership: Nurani Press

Suwandiyanto, M. 2010. Manajemen Strategi dan Kebijakan Perusahaan. Online

Tedjalaksana dan Aldiyanto. 2013. Strategic Management Planning of Soybean Store Hadijantotrisno with The Purpose of Develop in Business and Facing Competition. The Indonesian Journal of Business Administration, Vol 2.No.13: 1532-1547.

Undang-undang Nomor 1 Tahun 2004 tentang Perbendaharaan Negara

Walker, J.W. 1992. Human Resource Strategy. New York: Mc. Graw_Hill.Inc.

Widodo, Arry dan Setyorini, Retno. 2014. Pengaruh Kepemimpinan Transformasional dan Partisipasi Anggaran terhadap Kualitas Pelayanan melalui Variabel Intervening Manajemen Strategik di Pemerintah Daerah 
Perbatasan (Studi Kuasi pada Pemerintah

Daerah Provinsi Jawa Barat)

Proceedings SNEB.

Wheelen, Thomas L, Hunger, J.David. 2010. Strategic Management and Bussiness Policy Achieving Sustainability. Twelfth Edition. Pearson.

Yoanita dan Wandebori. 2013. Strategy Formulation and Implementation for Multigarmen Jaya. The Indonesian Journal of Business Administration, Vol.2. 1627-1636 